\title{
TECNOLOGIAS DE SABER-PODER SOBRE AS ÁGUAS: A EXPERIÊNCIA DO CONSELHO MUNDIAL DA ÁGUA'
}

\author{
Rodrigo de Freitas Espinoza ${ }^{a}$ \\ anniversidade Federal de São Carlos. São Carlos, SP, Brasil. \\ E-mail: rfespinoza@gmail.com \\ Orcid: 0000-0002-4384-8058 \\ Rodrigo Constante Martins ${ }^{b}$
}

- Professor do Departamento de Sociologia da Universidade Federal

de São Carlos. São Carlos, SP, Brasil.

E-mail:rmartins@ufscar.br

Orcid: 0000-0003-2700-3319

http://dx.doi.org/10.1590/0102-247280/113

\section{Introdução}

O Conselho Mundial da Água é uma organização internacional multilateral que se dedica a gerar ações e debates em torno das formas de regulação e financiamento do uso de recursos hídricos. Com base em estudos técnicos e na reunião de interesses envolvendo diferentes agentes sociais (sobretudo os do campo econômico), o Conselho está em atuação desde meados da década de 1990, no propósito de pautar o tema da água na agenda política global, se relacionando com governos nacionais, parlamentares e autoridades locais, bem como com outras organizações multilaterais, como as Nações Unidas.

\footnotetext{
1 A realização deste estudo contou com apoios financeiros da Fundação de Amparo à Pesquisa no Estado de São Paulo (FAPESP), do Conselho Nacional de Pesquisa e Desenvolvimento Tecnológico (CNPq), da Coordenação de Aperfeiçoamento de Pessoal de Nível Superior (CAPES) e do Institut de Recherche pour le Développement (IRD, França).
} 
Dentre as principais ações do Conselho está a organização periódica do Fórum Mundial da Água. Contando com um país sede em cada edição, o Fórum reúne diferentes participantes do que denomina por "comunidade da água”, incluindo agentes políticos, cientistas, da sociedade civil organizada e do setor privado. Desde sua criação, o Conselho teve atuação destacada no debate público sobre abastecimento de água, desenvolvimento sustentável, valoração econômico-ambiental, mudança climática, governança da água, parcerias público-privadas para a gestão hídrica e nexos entre água, energia e alimentação.

Devido à relevância do Conselho Mundial da Água no debate ambiental internacional, o objetivo deste artigo é analisar a produção discursiva da entidade em seus primeiros vinte e quatro anos de atuação. Com base na história da organização, esta pesquisa desenvolve-se a partir da compreensão do debate internacional sobre a questão ambiental como um 248 conjunto potencial de enunciados que, mesmo pertencendo a campos diferentes, partilham de ordens discursivas similares. Essas ordens discursivas estabelecem a organização do real por meio da produção dos saberes e das verdades compartilhadas, discriminando outras formas de saber que não se orientam por suas referências basilares. Nesse contexto, se observará que as circunstâncias históricas em que as modalidades de conhecimentos, supostamente tidas como universais, de fato se constituem como causa e efeito de seu tempo e, como tais, refletem agenciamentos interessados e orientados pela estrutura de campos de poder.

Adotando o referencial dos estudos pós-coloniais, o texto dialogará com análises sobre as construções discursivas nos espaços destinados ao debate internacional sobre água. Em interlocução com os estudos de Coronil (2005), Mignolo (2010), Castro-Gómez (2011), Grosfoguel (2012) e Ferdinand (2019), se argumentará que a produção de conhecimento técnico-científico sobre a temática ambiental - em especial, a água - revela 
uma construção discursiva que corrobora para a dinâmica de hierarquização de saberes que responde a uma polarização entre Norte/Sul e/ou Ocidente/Oriente globais.

Dentre os instrumentais teóricos mobilizados, a analítica de Foucault $(1996 ; 2018)$ acerca do poder, do discurso e do saber irá amparar a interpretação das narrativas sobre a gestão de águas difundidas pelo Conselho Mundial da Água. Este estudo também se baseará nas análises de Mbembe (2020) sobre o brutalismo e o modo como o poder, enquanto força geomórfica, produz fissuras, fraturações e efeitos sobre as classificações em torno da desigualdade e da diferença. Por fim, para avançar sobre o exercício de atribuição de formas, também se lançará mão da noção de justificação moral, empreendida pela sociologia pragmática de Boltanski e Thévenot, (1991), para se compreender os imperativos de discurso no debate internacional sobre meio ambiente.

Realizou-se um amplo levantamento documental, que compreendeu: (1) relatórios e documentos referentes às conferências dedicadas à água, como as de Mar Del Plata e de Dublin; (2) relatórios e documentos temáticos preparados e publicados pelo Conselho Mundial da Água, no período de 1997 (ano de sua criação) até 2020; (3) relatórios finais e cartas ministeriais produzidas nas oito edições dos Fóruns Mundiais da Água; além das trajetórias de formação e profissionais dos agentes fundadores do Conselho e de cada um de seus presidentes no período de 1997 a 2021.

\section{Conselho Mundial da Água}

Em 1994, a International Water Resources Association $(\text { IWRA })^{2}$ propôs a criação do Conselho Mundial da Água

\footnotetext{
2 A IWRA é uma rede internacional interdisciplinar de especialistas dedicados ao tema dos recursos hídricos. Fundada em 1971, em Wisconsin, EUA, a rede é uma organização não governamental, sem fins lucrativos e com predomínio de participação dos profissionais de engenharia. Desde 1975, edita o Water International, periódico de ampla circulação entre os pesquisadores dos recursos hídricos.
} 
durante os debates no VII Congresso Mundial da Água, realizado no Cairo, Egito. O tema principal do congresso era "Satisfazer demandas futuras nacionais e globais de água". Durante o encontro, uma seção especial foi organizada para a criação da resolução intitulada "Declaração de Cairo". Essa declaração propunha a criação do Conselho Mundial da Água e de uma comissão liderada pela IWRA para coordenar a tarefa. O objetivo era a formação de uma organização guarda-chuvas para unir esforços, até então fragmentados, sobre gestão global da água.

O comitê fundador do Conselho Mundial da Água realizou sua primeira reunião em Montreal, no Canadá, em março de 1995 e, no mesmo ano, teve um segundo encontro em Bari, na Itália. Essas reuniões definiram as diretrizes da entidade. Conseguinte, em 1996, o Conselho se estabeleceu formalmente em Marselha, na França, e teve a primeira reunião de sua diretoria interina em Granada, na Espanha.

250 Desde sua criação, o Conselho se autodefiniu como uma organização internacional com o propósito de promover a conscientização e os compromissos políticos que atuassem na preservação, proteção, desenvolvimento, planejamento e gestão dos recursos hídricos. Para tanto, estabeleceu-se que sua composição envolveria representantes de governos, universidades, sociedade civil, empresas e organizações nãogovernamentais. Sua estrutura foi constituída por um comitê, formado por 36 membros governadores e por instituições filiadas. Em 2020, o Conselho registrava mais de trezentas organizações como membros, espalhadas em pouco mais de cinquenta países.

A proposta de criação de uma entidade mundial dedicada ao debate público sobre a água esteve presente na Conferência Internacional de Água e Meio Ambiente, realizada na cidade de Dublin, na Irlanda, em janeiro de 1992. Na conferência, que reuniu diversos representantes de governos e de organizações não governamentais de mais 
de 100 países, foram sumarizados quatro princípios que balizaram os debates multilaterais posteriores relacionados às águas: (1) o reconhecimento da água como recurso finito e essencial à vida; (2) a indicação de que seu gerenciamento deveria ser caracterizado pela participação dos usuários em todos os níveis, bem como por planejadores e legisladores; (3) o reconhecimento do papel fundamental das mulheres na provisão e gestão das águas; (4) o reconhecimento do valor econômico e a indicação da relevância dessa dimensão na gestão do recurso.

A despeito da complexidade dos temas, o Conselho focou sua atuação no quarto princípio da declaração de Dublin. Embora a instituição tenha sido criada com o propósito de abrigar o debate global sobre a água, sua atuação esteve fortemente conduzida na direção da construção e justificação de discursos com imperativos morais voltados à regulação econômica do acesso e à comercialização dos recursos hídricos em todo o mundo.

Em junho de 1996, Mahmoud Abu-Zeid (Ministério das Obras Públicas e Recursos Hídricos, do governo do Egito), René Coulomb (empresa Suez Lyonnaise des Eaux, França) e Aly Shady (Canadian International Development Agency, Canadá) assinaram a declaração de criação do Conselho Mundial da Água. A trajetória desses três agentes, bem como as entidades que representavam à época, revelam questões importantes sobre a perspectiva e a orientação do modelo de gestão e construção discursiva que seria adotada pela entidade.

O egípcio Mahmoud Abu-Zeid é engenheiro civil de formação, com mestrado em engenharia de irrigação e doutorado em hidrologia de águas subterrâneas pela Universidade da Califórnia e tornou-se uma importante referência internacional nos estudos de hidrologia e gestão de recursos hídricos. Em 1972, tornou-se fellow do Instituto de Desenvolvimento Econômico, primeira designação do 
Instituto Banco Mundial. Academicamente, seu auge foi a posição de presidente da IWRA, no período de 1992 a 1994. Ocupou diferentes cargos ligados ao abastecimento de água e sistemas de irrigação no governo egípcio, chegando inclusive a ser Ministro de Estado de Recursos Hídricos e Irrigação de 1997 a 2009. Além disso foi presidente do Conselho Mundial da Água, de 1997 a 2006, e, durante sua gestão, participou da criação do Conselho Árabe da Água, em 2004. ${ }^{3}$

O segundo agente, o francês Réne Coulomb, foi vicepresidente da Suez Environment, de 1991 a 2000. Advogado do setor privado, Coulomb se consolidou, desde a década de 1980, como um dos principais assessores de empresas engajadas na defesa de marcos legais para a criação de mercados de água. O Grupo Suez, por sua vez, originouse da Compagnie Universelle du Canal Maritime de Suez, criada em 1858 para construir e explorar o canal de Suez. Com $252160 \mathrm{~km}$ de extensão entre o mar Mediterrâneo e o mar Vermelho, o canal foi inaugurado em 1869 e nacionalizado pelo governo egípcio em 1956. Esse episódio, que marcaria o conflito entre Egito e Israel, e resultaria na Guerra de Suez (ou ainda Guerra do Sinai), terminou por conduzir o Grupo Suez a diversificar seus investimentos em diferentes continentes, com ênfase em negócios nas áreas de gás, água e saneamento. Desde a década de 1990, o Grupo Suez se consolidou entre os maiores investidores no setor de abastecimento de água e serviços de esgoto do mundo, com atuação em cinco continentes.

Por fim, o terceiro membro fundador do Conselho Mundial da Água foi o engenheiro egípcio Aly Shady.

3 O Conselho Árabe da Água é formado por países árabes que estão abaixo da "linha de pobreza da água", com menos de mil metros cúbicos por ano por pessoa. É uma organização sem fins lucrativos que reúne governos, organizações não governamentais, setor privado, universidades e institutos de pesquisas regionais e internacionais. Em 2021, o Conselho reunia 450 membros de 22 países da região. Seu secretariado permanente fica no Cairo, no Egito. 
Formado na Universidade do Cairo, fez seus estudos de pós-graduação na Universidade McGill, em Montreal, no Canadá, tornando-se pesquisador do Departamento de Engenharia Agrícola da universidade. Em 1979, ingressou na Canadian International Development Agency (CIDA) que, integrada ao Ministério de Cooperação Internacional do Canadá, atua na promoção de estratégias de desenvolvimento sustentável, financiando projetos em países em desenvolvimento. Na Agência, Shady criou o Setor de Irrigação e internacionalizou sua carreira, desenvolvendo projetos em países das Américas do Sul e Central, na África, no Oriente Médio, na Ásia e no Leste Europeu.

A trajetória dos três agentes e a configuração das instituições que fundaram o Conselho Mundial da Água revelam as primeiras marcas das representações que sustentam um modelo específico de gestão ambiental. A CIDA é notadamente uma instituição de financiamento de projetos que busca dar apoio a países em desenvolvimento. Fundada em 1968, suas metas convergem para o princípio de que o Norte deveria ajudar os países pobres na superação da pobreza por meio da orientação voltada para o desenvolvimento sustentável. Já as outras duas entidades presentes na constituição do Conselho, IWRA e Suez, representam outras duas esferas centrais do moderno discurso sobre gestão, a ciência e o mercado. No caso da IWRA, é o seu caráter técnico que a legitima e lhe fornece prestígio no cenário global sobre a água, enquanto a Suez é uma das grandes empresas da economia global envolvidas no amplo campo do chamado negócio da água.

Desde sua fundação, o Conselho Mundial da Água articulou em torno de si agentes e instituições que viabilizaram a produção de um discurso sobre gestão das águas pautado na aproximação entre tecnociência e mercado, a trajetória dos agentes que presidiram a instituição desde sua fundação tem relação direta com este movimento de aproximação (Quadro 1). 
Quadro 1

Presidentes do Conselho Mundial da Água (1997-2021)

\begin{tabular}{|c|c|c|c|c|}
\hline Presidente & $\begin{array}{c}\text { País de } \\
\text { Origem }\end{array}$ & Mandato & Formação & $\begin{array}{c}\text { Entidade de } \\
\text { Origem }\end{array}$ \\
\hline $\begin{array}{c}\text { Mahmoud Abu- } \\
\text { Azeid }\end{array}$ & Egito & $1997-2006$ & Engenheiro Civil & $\begin{array}{c}\text { Banco Mundial } \\
\text { IWRA }\end{array}$ \\
\hline $\begin{array}{c}\text { William } \\
\text { Cosgrove }\end{array}$ & Canadá & $2006-2009$ & $\begin{array}{c}\text { Engenheiro } \\
\text { Sanitarista }\end{array}$ & $\begin{array}{c}\text { Ex-vice- } \\
\text { presidente do } \\
\text { Banco Mundial }\end{array}$ \\
\hline Loïc Fauchon & França & $2009-2012$ & Economista & $\begin{array}{c}\text { Société des Eaux } \\
\text { de Marseille }\end{array}$ \\
\hline Benedito Braga & Brasil & $2012-2018$ & $\begin{array}{c}\text { Engenheiro } \\
\text { Hidráulico }\end{array}$ & $\begin{array}{c}\text { ANA } \\
\text { IWRA }\end{array}$ \\
\hline
\end{tabular}

Fonte: Elaboração própria.

Distanciando-se do terceiro princípio da Declaração de Dublin, que lançara luz ao papel desempenhado pelas mulheres na gestão e proteção da água, o Conselho contou com absoluto predomínio masculino, tanto entre seus agentes fundadores quanto entre aqueles que o presidiram nos seus primeiros vinte e quatro anos (1997-2021). Os quatro agentes que já exerceram o cargo de presidente do Conselho Mundial da Água possuem trajetórias semelhantes e representam, pela formação profissional e trânsitos institucionais, uma categoria específica de saberes legítimos para tratar do tema da água.

Mahmoud Abu-Zeid, além do que já foi citado, foi colaborador de diversas instituições multilaterais, muitas das quais ligadas às Nações Unidas, como a FAO (Food and Agriculture Organization), a UNEP (United Nations Environment Programme) e a UNESCO (United Nations Educational, Scientific and Cultural Organization). Zeid 
também foi vice-presidente da IWRA e presidente do Programa Internacional de Hidrologia da UNESCO.

William J. Cosgrove, o segundo presidente, também é membro do Conselho desde 1996. Iniciou seu trabalho no Banco Mundial, como especialista de recursos hídricos em regiões da África e do Oriente Médio, chegando à vicepresidência da entidade na década de 1980, cargo que exerceu até 1989. Assim como Zeid, Cosgrove também é membro da IWRA.

O terceiro a ocupar o cargo foi Loïc Fauchon, que presidiu o Conselho em dois períodos: de 2009 a 2012 e de 2018 a 2021. Formado em Economia pela Universidade de Aix-en-Provence, na França, foi chefe de gabinete e secretário-geral da cidade de Marselha entre os anos de 1991 e 1997. Desde 1992 Fauchon trabalharia, também, no grupo Société des Eaux de Marseille, assumindo a presidência da entidade em 1997. Essa organização, por sua vez, é subsidiária da Veolia Environment, um dos maiores grupos privados de gestão de água e resíduos do mundo. Recentemente, em 2021, adquiriu o restante das ações que ainda não detinha da Suez, reafirmando seu destaque no setor.

Benedito Braga foi o quarto presidente do Conselho, à frente da instituição entre os anos de 2012 e 2018. Formado em Engenharia Hidráulica pela Universidade de São Paulo (USP), é doutor em recursos hídricos pela Universidade de Stanford, nos Estados Unidos. Braga fora assessor especial da Secretaria de Energia e Saneamento do Estado de São Paulo e diretor da Agência Nacional de Águas, desde a criação até 2009, somando nove anos. Foi ainda presidente da IWRA entre 1998 e 2000. Na crise hídrica paulista iniciada em 2014, Braga foi convidado pelo então governador do Estado de São Paulo, Geraldo Alckmin, a assumir a Secretaria Estadual de Saneamento e Recursos Hídricos. No ano de 2018, no governo de João Dória Junior, tornou-se diretor presidente da Sabesp. 
Vale destacar ainda que em 2000, o Conselho Mundial da Água lançou o documento intitulado "World Water Vision: Making Water Everbody's Business" elaborado pela World Water Commission, que era composta por nomes como: Jerôme Monod, da Suez Lyonnaise des Eaux; Maurice Strong, membro da Business Council on Sustainable Development (WBCSD); Robert S. MacNamara, então presidente do Banco Mundial; Enrique Iglesias, presidente do Banco Interamericano de Desenvolvimento (IADB); Mohamed T. El-Ashry, CEO do Banco Mundial e membro do UN Global Environment Facility à época. Sem embargo, a geopolítica dos agentes promotores do discurso de mercado presente no documento é, um importante indicador do papel estratégico de instituições como o Conselho na implementação da agenda neoliberal das águas e na relação desigual entre o centro e a periferia capitalista.

No início dos anos 2000, a expectativa era de que água 256 se tornaria um grande negócio global. Tal expectativa pode ser observada em reportagem de Shawn Tully para a revista Fortune, publicação estadunidense de grande alcance, dedicada ao campo da economia e finanças, o destaque da reportagem era o que se segue: "Água, Água em todo lugar hoje. Empresas como a francesa Suez estão correndo para privatizar a água, que já é um negócio global de US \$ 400 bilhões. Eles apostam que H2O será para o século 21 o que o petróleo foi para o século 20"4 (tradução livre).

O contexto histórico e as instituições que participaram da fundação do Conselho, bem como as trajetórias de seus presidentes, indicam um regime de verdade e de (di) visão de mundo. Como enfatizado por Martins (2015), na construção da moderna questão ambiental e de alguns de seus corolários (como as noções de desenvolvimento sustentável e de gestão racional da água), há o emprego recursivo de um sistema

4 Tully, S. Water, Water Everywhere. Fortune Magazine, 15 de maio, 2000, p. 55. 
classificatório da realidade socioambiental que tem profundo enraizamento no território disciplinar da Economia Ambiental. ${ }^{5}$ Ou seja, a disposição das especialidades no espaço de nominação legítima da moderna crise socioambiental resulta de arranjos entre paradigmas da ciência econômica e das áreas de tecnologia para a gestão ambiental.

Ademais, no caso dos fundadores e presidentes do Conselho Mundial da Água, o grupo de agentes participa do debate público-ambiental internacional, tanto mobilizando o repertório disciplinar de suas áreas de formação quanto valorizando as intervenções, desde suas atuações em instituições do norte global, voltadas à produção de saberes e tecnologias sociais para a resolução de problemas e conflitos em países pobres do sul global.

Sobre a disposição assimétrica entre o norte e o sul, Grosfoguel (2012) aponta um movimento comum nos debates que se pretendem globais. O esforço dos intelectuais do sul em citar e buscar diálogos com pensadores europeus se consolida como uma via de mão única. $\mathrm{O}$ norte é surdo às vozes do sul, e se entende como universal a partir da surdez e do não-diálogo. A produção teórica, assim elaborada, turva as noções de eurocentrismo e universalismo sem qualquer constrangimento dessa fusão. Nesse aspecto, o trânsito de agentes do sul para instituições do norte legitima a instituição como global, ao mesmo tempo em que conserva a assimetria de poder entre os polos.

No caso do Conselho, a incorporação das populações marginalizadas na lógica de gestão econômica da água responde a uma dinâmica de consolidação desse modelo como universal. Como descreve Moreno (2005), não é raro que centros hegemônicos do norte global adotem uma postura de vanguarda que não se propõe a alterar o arranjo

\footnotetext{
${ }^{5}$ Para pormenores dos fundamentos da Economia Ambiental no marginalismo neoclássico, ver Pearce (1985) e Pearce e Turner (1991).
} 
sociopolítico e econômico, que provoca desigualdades geopolíticas e ambientais; pelo contrário, observamos a ação de capacitar a população para a integração a uma ordem social supostamente superior.

Assim, mercado e cidadania seriam sistemas cujas regras de coexistência teriam baixa assimilação da parte dos grupos sociais marginalizados. A inclusão desses grupos, mediante programas de capacitação para a participação e cidadania socioambiental, asseguraria, por sua vez, o caráter absoluto e universal desses sistemas, a história geopolítica e colonial da degradação ambiental é deslocada do debate em favor de abstrações como "sujeito global" ou "humanidade em geral", a fratura colonial da modernidade invade a própria ecologia como força discursiva, negligenciando o fato histórico de que o moderno sistema colonial se amparou no racismo e no patriarcado para estabelecer a divisão social da exploração dos recursos naturais (Ferdinand, 2019). De tal sorte 258 que, sob a abstração da "população" ou da "humanidade em geral", a construção do norte sobre a crise ecológica termina por apagar o fato colonial.

\section{A visão do Conselho sobre gestão da água}

Desde sua criação, o Conselho Mundial da Água publica documentos classificados como relatórios temáticos e de atividades, em que a entidade registra seus discursos e posições sobre a gestão dos recursos hídricos. Tais publicações são amparadas em uma retórica que articula o conhecimento de áreas politécnicas com as categorias de classificação da realidade social produzidas pelo utilitarismo econômico.

Após três anos de sua criação, o Conselho publicou o que seria, segundo a entidade, a "Visão Mundial sobre a Água”. Lançado em 2000, esse documento é central para se compreender a agenda e a orientação adotada pela entidade sobre o recurso. Situando-se como porta-voz privilegiado, amparado na ciência e na racionalidade do capital 
econômico, o Conselho insiste na relevância estratégica da valoração econômica da água para solucionar as situações de crise de acesso e gestão dos recursos hídricos, conforme registra o próprio documento:

Precificar os serviços de água ao custo total. Fazer com que a água esteja disponível a baixo custo, ou gratuitamente, não fornece o incentivo certo para os usuários. Os serviços de água devem ser valorizados pelo custo total para todos os usuários, cobrindo todos os custos relativos à operação e manutenção para todos seus usos e custos de investimento, ao menos, para usos domésticos e industriais. $\mathrm{O}$ requisito básico é que a água precisa ser acessível a todos, no entanto, a tarifação dos serviços de água não significa que os governos devam desistir dos subsídios transparentes e direcionados para os pobres. (World Water Council, 2000, p. XXIV. Tradução livre)

Entende-se, a partir desse trecho, que o princípio da valoração econômica da água pressupõe que os usuários do recurso devem ser alçados à condição de efetivos consumidores, pagando financeiramente pelas flutuações locais ou regionais de sua disponibilidade. Desse modo, os usuáriosconsumidores receberiam a sinalização de que a água, em situação de escassez, teria seu valor monetário refletido visà-vis um sistema de livre mercado, em direção a um regime ultraliberal de política ambiental (Acselrad, Mello e Bezerra, 2009), que o papel dos governos se restringiria ao estabelecimento de metas e políticas de subsídios para atender aos mais pobres. ${ }^{6}$

O princípio da valoração econômica é pautado nos documentos do Conselho como produto do saber

\footnotetext{
${ }^{6}$ A propósito da formulação da valoração econômica da água como instrumento de gestão ambiental, bem como de suas extensões (e implicações) sociopolíticas, ver Martins (2013).
} 
técnico-científico, a própria noção de utilidade é recorrentemente citada como produto natural do comportamento dos agentes econômicos, cuja conduta moral seria voltada inequivocamente - ou instintivamente, como diria Smith (2015) - para a maximização dos prazeres (ganhos) e minimização das dores (custos) individuais. Em um esforço de modelagem e de síntese brutalista, ${ }^{7}$ economia e gestão ambiental seriam campos privilegiados do saber, em que à ciência econômica caberia a compreensão adequada desses cálculos individuais de custo-benefício e à gestão ambiental se atribuiria o papel de internalizar os constrangimentos dos custos econômicos da degradação ambiental nos cálculos dos agentes econômicos.

Sendo assim, o tema da valoração econômica da água é apresentado pelo Conselho como produto de um discurso que se autodefine como eminentemente técnico. Enquanto os discursos contrários à valoração e à privatização são classificados como produtos de agendas políticas arcaicas e ineficientes (apoiadas nos ideais de regulação do Estado, controle jurídico das formas de uso etc.), a argumentação favorável ao cálculo econômico é sustentada pelo Conselho justamente por seu caráter neutro e democrático, posto que se ampara no saber técnico da ciência e na liberdade política do mercado.

Os documentos publicados pelo Conselho a partir de então descreverão tanto suas atividades e programas, como reiterarão esta visão sobre a gestão da água. No relatório publicado pela organização sobre o triênio 2000/2003 período que compreendeu a realização do $2^{\circ}$ Fórum Mundial da Água -, Mahmoud Abu-Zeid, então presidente da entidade, afirmou que:

\footnotetext{
7 Ao extrair o conceito de brutalismo da arquitetura, Mbembe (2020) ressalta seu conteúdo eminentemente político. Isso porque, para o autor, toda política é um esforço de dar forma, um exercício de modelagem, seja sobre os materiais, seja sobre as demais dimensões da vida - incluindo aqui o que a tradição sociológica designa por simbólico.
} 
As principais questões discutidas pelos participantes no $2^{\circ}$ Fórum foram privatização, cobrança do custo total para os serviços de água e direitos de acesso e participação.

A Declaração Ministerial identificou a satisfação das necessidades básicas relacionadas à água, a garantia alimentar, a proteção do ecossistema, a partilha dos riscos ligados à gestão dos recursos hídricos, valoração da água e boa governança como os sete desafios-chave para o nosso futuro. Aspectos da globalização e do comércio podem ser considerados também como questões emergentes segundo a declaração de Haia. (World Water Council, 2003a, p. 2. Tradução livre)

A rigor, a participação do setor privado na gestão é apresentada nos documentos do Conselho como dado indiscutível, força da racionalidade econômica individual ante a ineficiência da gestão pública, ademais, essa participação se adequaria à necessidade de financiamento para a ampliação do abastecimento para fins de produção econômica (agricultura e indústria) e usos domésticos. O modelo de gestão com parceria público-privada (PPP) passaria, então, a ter amplamente a seguinte definição:

O fortalecimento do setor público é necessário para assegurar uma regulamentação adequada e um controle público sobre os recursos comuns. O envolvimento do setor privado, por meio de parcerias público-privadas, no fornecimento de serviços de água e na contribuição para o financiamento de investimentos é uma necessidade absoluta para o futuro. Isso requer marcos regulatórios previsíveis e transparentes que protejam os interesses dos investidores e dos consumidores. (World Water Council, 2003a, p. 3. Tradução livre)

A necessidade da participação do setor privado é dada como ponto indiscutível porque a crise da água, como 
o próprio Conselho relata, seria a crise de um modelo pouco aberto à absorção dos sinais de mercado. Isto é, a crise não teria relação com as formas de uso intensivo promovidas pelo regime de acumulação de capital. A subjetividade universal do agente econômico abstrato é mobilizada como alvo a ser alcançado pelos instrumentos econômicos de gestão ambiental, a argumentação se desenvolve rumo à classificação polarizada - e não menos colonial - dos países desenvolvidos e países em desenvolvimento. Ainda no discurso do então presidente da entidade, a ideia de promover o comportamento racional e o desenvolvimento nos países mais pobres passaria, necessariamente, por modelos com suporte financeiro externo que fossem atraentes para esse capital.

Ainda não está claro até que ponto as organizações doadoras bilaterais e multilaterais planejam participar no apoio financeiro necessário para atender às necessidades dos países em desenvolvimento para as próximas duas décadas. O Conselho e seus parceiros serão proativos em trazer este debate para os conselhos de administração dessas instituições e estimular o desenvolvimento de modelos de financiamento atraentes e realistas. (World Water Council, 2003a, p. 3. Tradução livre)

A propósito do papel do Conselho Mundial da Água no debate internacional sobre a questão ambiental, Espinoza (2016) remonta à atuação da entidade nas grandes conferências temáticas, revelando como seu ponto de vista não é apresentado nesses espaços como particular e singular, mas, sim, como síntese da compreensão racional sobre o tema em termos econômico e técnico-científico. Entretanto, ainda que mobilizasse diferentes modalidades de capital para legitimar seu discurso, as resistências se faziam presentes mesmo nos espaços de protagonismo do Conselho, como foi o caso da discussão sobre as parcerias 
público-privadas no $3^{\circ}$ Fórum Mundial da Água, realizado em 2003, na cidade de Kyoto, no Japão.

As parcerias público-privadas mantiveram-se como uma das principais controvérsias em Kyoto. O Conselho foi o coordenador do tema Parcerias Público-Privadas durante o $3^{\circ}$ Fórum, juntamente com o Council of Canadians. ${ }^{8}$ A discussão em Kyoto entre os prós e contras a participação do setor privado foi um confronto de natureza ideológica com os grupos "antiprivatização", que são muito sensíveis à globalização e liberalização de comércio. Esses grupos também alertam para o possível conflito de interesses na gestão dos serviços públicos de água e da gestão dos recursos hídricos. A discussão centrou-se principalmente sobre a propriedade dos recursos públicos como a água, sua gestão e os princípios orientadores da política de preços, além da questão ética da obtenção de lucro em serviços públicos. A privatização real no setor da água significaria que a propriedade dos recursos hídricos e políticas de preços estariam nas mãos do setor privado. Isto não é apoiado pelo Conselho Mundial da Água. (World Water Council, 2003a, p. 12. Tradução livre)

Sob a perspectiva do Conselho, a privatização da água não estaria entre as metas para o aprimoramento da gestão do recurso. A entidade já defendia no relatório de 2003, e seguiria defendendo nos relatórios seguintes, a garantia do status do recurso como bem comum, mas dotado de valor econômico. Caberia, portanto, a atuação de um poder

${ }^{8}$ O Council of Canadians é uma organização sem fins lucrativos que atua na defesa da água limpa, da energia verde, da saúde pública e do comércio justo. Com sede em Ottawa, a organização tem atuação nacional (Canadá) e, desde 2012, também internacional, por meio do projeto Planeta Azul. O projeto se dedica ao acompanhamento da resolução 64/292 da ONU, aprovada em Assembleia Geral de julho de 2010, que declarou o acesso à água limpa e ao saneamento como direitos humanos essenciais. 
regulador - do Estado ou de instâncias mistas de governança - capaz de sinalizar o valor econômico do recurso, de modo a refletir junto aos seus usuários a situação de escassez relativa ante os fluxos de oferta e demanda.

Mesmo supondo distância da privatização da água, a mediação da relação sociedade-natureza como efeito dos sinais de mercado converge para o processo descrito por Coronil (2005) como globocentrismo. Esse conceito pode ser entendido como uma modalidade de ocidentalismo e refere-se à submissão de populações por meio dos efeitos de mercado. Dessa forma, a concepção de Ocidente dilui-se no mercado e estabelece nódulos de poder financeiro menos visíveis e mais concentrados. Ademais, a alteridade é substituída pela subalternidade na diferenciação cultural, em um processo de ordem ocidentalizada com forma aparente de simples mecanismo de mercado e produto da tecnociência

Com efeito, a ordem ambiental internacional, como 264 descrita por Ribeiro (2010), vem se consolidando como uma das questões mais importantes do século XXI, enquanto, paralelamente, o complexo contexto geopolítico segue imerso em tensões sobre os rumos de regulação da relação sociedade-natureza. Nesse cenário, a polarização entre os países desenvolvidos e em desenvolvimento se configura em uma arena relevante de lutas e arranjos. Mas, para além da abstração da "nação", convém acompanhar as relações entre classes e grupos/elites econômicas que transformam os modernos desafios ambientais em novas frentes de produção de capital econômico. Importante destacar que o Conselho Mundial da Água protagoniza a ampliação dessas frentes, assumindo, inclusive, a incorporação da crítica à acumulação capitalista, nos termos sugeridos por Boltanski e Chiapello (2009).

O protagonismo na incorporação da crítica pelos agentes econômicos também se revela na atuação do Conselho junto à Organização das Nações Unidas (ONU). O relatório 
do Conselho relativo ao triênio de 2010-2012 demonstra seu forte movimento em direção aos espaços organizados pela ONU, para apresentar-se como representante da água nos debates internacionais sobre meio ambiente, se autodenominando "A voz da água" (The Voice of Water) e se autodeclarando hidrodiplomata internacional.

Os tomadores de decisões políticas devem demonstrar uma vontade genuína de incluir a água como prioridade.

O Conselho tem, portanto, colocado muito foco em expressar a voz da água, fazendo o que veio a ser conhecido como "hidrodiplomacia internacional". A causa da água só vai ter progresso quando for debatida de forma pacífica e objetiva. Essa visão converge com a das Nações Unidas, cujo Secretário-Geral, Ban Ki-moon, deu ao Conselho o seu total apoio durante uma audiência individual em outubro de 2010, quando ele convidou a delegação da organização para a sede da ONU, em Nova York. Ele apoiou o Presidente para transformar o Conselho em uma organização internacional reconhecida e respeitada e pediu ao Conselho que esteja intimamente envolvido na preparação da Rio+20, em 2012. (World Water Council, 2012a, p. 7. Tradução livre)

A associação do Conselho a grandes instituições multilaterais o colocou em condição de participar ativamente na organização do debate público-ambiental, além de legitimar paulatinamente sua condição de agente privilegiado para expor os interesses de seus membros. Como exemplo disso, pode-se citar a proposição da parceria entre o Conselho e a Organização para Cooperação e Desenvolvimento Econômico (OCDE), em 2014, para a criação de um grupo especial destinado a discutir o financiamento de infraestrutura para segurança hídrica. Como resultado da parceria, foi lançado o relatório "Water: Fit to Finance", no 7ํㅜórum Mundial da Água, em 2015. 
O relatório é atravessado pela posição histórica do Conselho sobre o tema, destacando a necessidade crescente da criação de parcerias público-privadas para a construção de projetos de infraestrutura ligados à água. Em sua principal conclusão, há a afirmação de que: “o painel apontou uma racionalidade de 'risco e recompensa' entre os investidores como uma barreira, o que resultou em uma marginalização dos projetos de infraestrutura de água em comparação a outros ramos de investimento em infraestrutura" (World Water Council, 2015, p. 17).

Em seu conjunto, os relatórios de atividades publicados pelo Conselho demonstram não apenas a atuação intensa da entidade, mas também - se não mesmo principalmente o discurso saber-poder sobre a água promovido e lançado pela entidade no debate público-ambiental internacional. Nesse discurso, a universalidade das categorias científicas e dos instrumentos econômicos de gestão cumpriria, dentre outras,

266 a função de absolutizar as estratégias de enfrentamento dos contextos de crises no uso e acesso à água, além de tornar opaca a força que certos marcadores sociais (classe, raça e etnia) poderiam revelar no contexto geopolítico da água.

\section{Os Fóruns Mundiais da Água}

Nas últimas três décadas, os Fóruns Mundiais da Água assumiram gradativamente papel de grande relevância no debate público-ambiental internacional, consolidando-se como o maior evento dedicado ao tema. Desde sua primeira edição, em 1997, o Fórum é realizado a cada três anos, reunindo representantes governamentais, organizações internacionais, organizações não-governamentais (ONGs), instituições financeiras e indústrias. Já foram realizadas oito edições do Fórum, em países diferentes. A nona edição será realizada em 2021, em Dakar-Senegal. Como se pode observar na Figura 1, esta será a segunda edição do Fórum no continente africano. 
Figura 1

Realização do Fórum Mundial da Água, por ano e local (1997-2021)

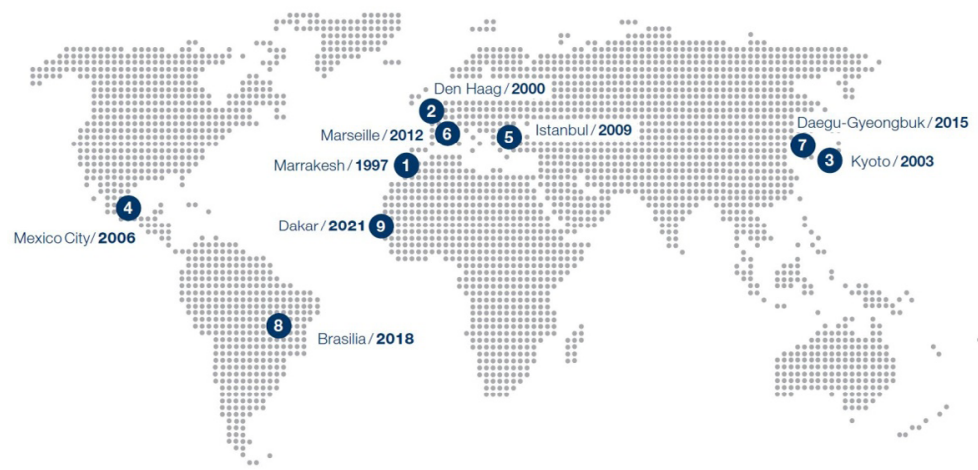

Fonte: World Water Concil. Disponível em: https://bit.ly/2V2gXzV. Acesso em: 5 fev. 2021.

Não se pretende aqui remontar o conjunto das atividades e debates travados em cada uma das edições do Fórum. Tampouco se buscará revisar a distribuição geopolítica do conjunto dos participantes. Mas, com base nos relatórios finais de cada uma delas, serão destacadas as principais sínteses anunciadas pelo próprio Conselho Mundial da Água, bem como o alcance do Fórum em termos de público e número de países participantes.

Em sua organização, as edições do Fórum se estruturam em quatro divisões principais: o processo temático, o processo político (que se dá em escala ministerial, parlamentar e local), os processos regionais e o processo cidadão (que conta com a participação da sociedade civil organizada). Cada edição contou com a realização de dezenas de mesas de debates e exposições dos mais variados temas.

O documento final de maior destaque nesses eventos são as declarações ministeriais, em razão de seu caráter de resultado das diversas discussões empreendidas em cada encontro. $\mathrm{O}$ documento é comumente genérico e pouco deliberativo, pois depende de alto grau de consenso entre 
os representantes de governos nacionais. De maneira breve, pode-se descrevê-los como documentos que convergem para questões majoritariamente aceitas e cristalizadas no cenário do debate internacional sobre a água.

No entanto, por essa mesma razão, as declarações ministeriais formam um importante material de investigação. É possível observar, por exemplo, que a visão particular que o Conselho exprime em seus documentos não é contraposta pelas declarações ministeriais das edições do Fórum. Ou seja, a construção discursiva da agenda do Conselho é amplamente aceita e expressa de maneira consensual nas publicações.

O $1^{\circ}$ Fórum Mundial da Água foi realizado em março de 1997, em Marrakech, no Marrocos. O encontro contou com 500 participantes de 63 países. Na ocasião, foi elaborada a "Declaração de Marrakesh", que estabelecia a importância do Conselho para a temática da água. Nesta ocasião, o Conselho Mundial da Água recebeu o mandato para 268 desenvolver um relatório sobre a Visão Mundial da Água para a Vida e o Meio Ambiente para o século XXI.

Já o $2^{\circ}$ Fórum foi realizado em Haia, na Holanda, em março de 2000, e teve como principal resultado a elaboração da Declaração de Haia sobre a segurança da água para o século XXI. O tema geral do evento foi intitulado "Da visão para a ação". Nesse fórum, o número de participantes subiu para 15.700 pessoas, contando com 144 ministros e representantes oficiais de 130 países. Nesse evento foi lançado o documento intitulado Visão Mundial da Água: fazendo da água um negócio para todos.

O debate sobre a participação do setor privado se aprofundou no $3^{\text {o }}$ Fórum Mundial da Água, realizado em Kyoto, Shiga e Osaka, no Japão, em 2003. As publicações do Conselho já haviam sido referências para os debates ocorridos na Cúpula do Milênio das Nações Unidas (2000) e na Conferência Internacional de Água Potável de Bonn (2001), bem como na Cúpula Mundial sobre Desenvolvimento 
Sustentável (a Rio+10, realizada em 2002). A terceira edição do Fórum se tornaria o maior evento sobre a temática da água até então realizado. Mais de 24 mil pessoas participaram do encontro, incluindo sei mil não japoneses e 1.300 delegados como representantes oficiais de 170 países. A Conferência Ministerial teve participação de 130 ministros e foi ainda acompanhada por 47 organizações internacionais.

Na Figura 2 estão destacados os países que tiveram representantes na Conferência Ministerial da terceira edição do Fórum, e observa-se uma baixa representação dos países americanos e uma representação parcial dos países africanos.

\section{Figura 2}

Países com representantes na Conferência Ministerial do 3o Fórum Mundial da Água (2000)
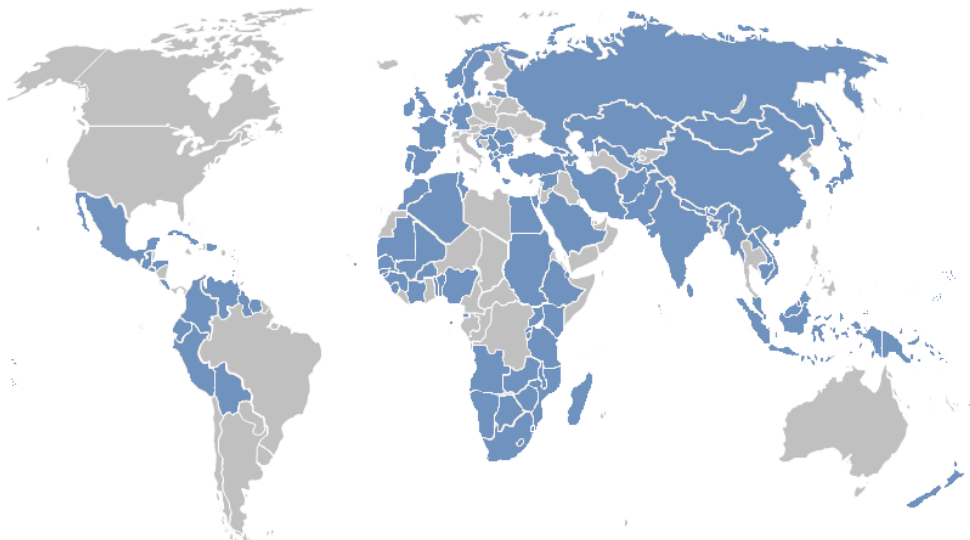

Fonte: Elaboração própria.

Neste $3^{\circ}$ Fórum, construiu-se a assertiva de que a água não deveria ser um recurso sob monopólio do Estado, muito embora isso não significasse que devesse ser privatizada. Ao contrário, a água deveria ser tratada como uma propriedade comum, a despeito das contradições que isso possa trazer.

A posição do Conselho fora sintetizada do seguinte modo: 
A posição do Conselho neste debate reflete a opinião da grande maioria dos participantes, embora também houvesse fortes argumentos opostos de alguns grupos da sociedade civil sobre a questão fundamental da participação do setor privado nos serviços de água. O Conselho declara que (i) uma ampla gama de soluções pode ser possível para administrar com sucesso serviços públicos de água e que (ii) as autoridades locais devem ser capazes de fazer suas próprias escolhas, tendo em conta as suas capacidades e os desejos de sua população. Em todo caso, ajudar o setor privado local para reforçar as suas capacidades também é fundamental para o desenvolvimento dos seus países. (World Water Council, 2003b, pp. 22-23. Tradução livre)

A Declaração Ministerial produzida nesse encontro levantou 29 pontos, dos quais merece especial destaque o ponto 6, que possui convergência importante com o posi270 cionamento do Conselho:

6. Devemos explorar toda a gama de mecanismos de financiamento, incluindo a participação do setor privado, alinhada com as nossas políticas e prioridades nacionais. Vamos identificar e desenvolver novos mecanismos de parcerias público-privadas para os diferentes atores envolvidos, assegurando o controle público necessário e quadros legais para proteger os interesses públicos, com particular ênfase na defesa dos interesses dos pobres. (World Water Council, 2003c, p. 110. Tradução livre)

Isso demonstra que os resultados, a priori entendidos como consensuais, também devem ser interpretados como perspectivas hegemônicas, resultantes de relações de força e de sentido. Isso porque o discurso expresso no documento não expressa apenas a luta e o conflito de interesses, mas é também aquilo o motivo pelo qual se luta, de tal sorte que 
a diversidade de posicionamentos e ideias postas em circulação no evento não foram sistematizadas ou registradas em seus documentos finais.

Embora o Conselho sinalize a presença de uma forte oposição de setores da sociedade civil, o discurso dessa oposição não está registrado nos documentos finais do evento. $\mathrm{O}$ mesmo não ocorre com o posicionamento do Conselho, nesse caso, sua posição se insere integralmente à Declaração Ministerial.

Em 2006, foi realizado o 4ํㅜㅇón Mundial da Água, na Cidade do México, sob o tema "Ações Locais, Desafios Globais". Cerca de vinte mil participantes estiveram presentes em mais de duzentas sessões temáticas e trezentas organizações representavam 51 países. Segundo Ribeiro (2008), esta edição registrou um número inédito de acordos bilaterais, em especial sobre águas subterrâneas. A participação dos países com representantes na Conferência Ministerial se ampliou significativamente, como observa-se na Figura 3. Entretanto, as construções discursivas presentes nos documentos finais do Fórum não sofreram mudanças significativas sobre as orientações para a gestão das águas.

\section{Figura 3}

Países com representantes na Conferência Ministerial do IV Fórum Mundial da

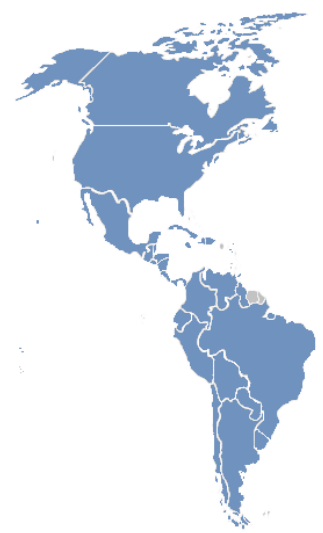
Água (2006)

Fonte: Elaboração própria.

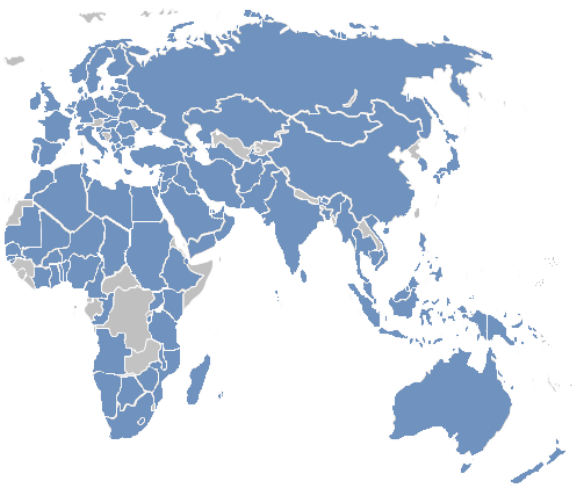


O $5^{\text {o }}$ Fórum Mundial da Água foi realizado em 2009, em Istambul, na Turquia, e reuniu trinta mil participantes de 182 países. Da Declaração Ministerial produzida no encontro, destaca-se a ênfase para a criação de um ambiente propício a investimentos no setor de água e saneamento, além do discurso sobre a necessidade de ajuda da comunidade internacional para complementar os investimentos feitos por países em desenvolvimento ou com uma economia em transição.

Realizado em 2012, mesmo ano da Rio+20, o 6oㅜ Fórum foi sediado em Marselha, na França. O encontro reuniu participantes de 145 países e manteve a ênfase nas discussões sobre o financiamento da água para todos e a criação de ambientes propícios aos investimentos. Em consonância com o discurso do Conselho Mundial da Água, a Carta Ministerial do Fórum ressaltaria a necessidade de um modelo de gestão que proporcionasse altos investimentos no setor de abastecimento. Seja amparado pelo setor pri272 vado, público ou por agências multilaterais, como o Banco Mundial, este plano deve ser um ambiente seguro, não necessariamente para a preservação ambiental, mas para a alocação de altos investimentos.

Para se fazer valer, esse discurso socialmente enraizado e politicamente interessado mobilizaria imperativos de justificação próprios das trocas mercantis. Ao naturalizar essas trocas, se ordenaria que o discurso-realidade de justiça e equidade seriam naturalmente produzidas por meio das tecnologias sociais do mercado. Por isso, dentre seus imperativos morais, estava a crença de que os governos nacionais são invariavelmente ambientes inseguros para o investimento externo. Como desdobramento, também se observa a certeza de que as instituições internacionais e o próprio mercado são espaços superiores para a realização das potencialidades sociais e para a consequente promoção do desenvolvimento em países do sul global, carentes de investimentos. Sob tais imperativos morais, tanto a natureza quanto a população em condições 
de pobreza seriam, portanto, beneficiadas com a condução econômico-racional da gestão das águas.

Vemos tais informações em conformidade com o ponto 26 da Declaração Ministerial do $6^{\circ}$ Fórum:

26. A priorização da água e saneamento nas alocações de verbas e na cooperação internacional é fundamental, bem como a utilização eficaz dos instrumentos financeiros. Vamos promover o planejamento financeiro estratégico e sustentável, por meio de uma combinação adequada de contribuições de usuários de água, orçamentos públicos, financiamento privado, bilateral e canais multilaterais. Reconhecemos a necessidade de recuperação economicamente sustentável e eficiente, a favor dos pobres e com mecanismos de financiamento inovadores, como pagamento apropriado para os serviços prestados pelos ecossistemas e investimento privado, num espírito de solidariedade, justiça e equidade. (World Water Council, 2012b, p. 5. Tradução livre)

O $7^{\circ}$ Fórum foi realizado em 2015, em Daegu e Gyeongju, na Coreia do Sul, e reuniu mais de quarenta mil participantes, com 106 representantes. Já o $8^{\circ}$ Fórum foi realizado em Brasília, no Brasil, no ano de 2018, e reuniu 172 países. O público total esteve próximo de 120 mil pessoas. Em grande medida, o expressivo número de participantes se deve à organização de uma Vila Cidadã, que reuniu pouco mais de 58 mil crianças inscritas.

As atividades da edição brasileira do Fórum foram organizadas em consonância às discussões empreendidas nos documentos publicados pelo Conselho Mundial da Água no ano anterior. Assim como os outros, esses documentos enfatizavam a necessidade de avanços nas formas de valoração econômica da água e a meta de catalisação de parcerias públicoprivadas para enfrentar as necessidades de financiamentos para a segurança hídrica local e internacional-principalmente 
no continente africano (World Water Council, 2018a; 2018b; 2017). A Declaração Ministerial do encontro, por sua vez, manteve o alinhamento político com as declarações dos últimos Fóruns. Destacou-se, portanto, dessa edição, a necessidade do combate à pobreza, a prestação de contas de arranjos institucionais acerca da água, o financiamento e a gestão e o incentivo à cooperação transfronteiriça.

Como se pode observar nessa breve retrospectiva, a ampliação da visibilidade dos Fóruns Mundiais da Água nos últimos vinte e quatro anos demonstra a importância que a questão da água tomou no cenário mundial. Entretanto, é possível observar também que a construção discursiva sobre a crise desse recurso e as formas para sua solução caminham para uma perspectiva específica de gestão.

Os fóruns apontam que a crise da água é, sobretudo, uma crise de gerenciamento e governança. O poder público, em especial nos países em desenvolvimento, não possui 274 a capacidade técnica e financeira para atender à demanda pelos recursos hídricos e, por isso, a participação do setor privado apresenta-se como solução para enfrentar o problema da gestão e de seu financiamento.

A construção discursiva sobre a crise do acesso à água e ao saneamento básico estabelece que esses são problemas que só podem ser solucionados através da incorporação da lógica de mercado à gestão da água. Esse argumento não se restringe a possíveis interesses de grupos privados que buscam conquistar mercados. É parte fundante do argumento de que o direito à água só pode ser alcançado pelo e no mercado, como bem acentua Quijano (2005, p. 236):

As determinações capitalistas exigiam também, e no mesmo movimento histórico, que esses processos sociais, materiais e intersubjetivos não tivessem lugar exceto dentro de relações sociais de exploração e de dominação. Consequentemente, como um campo de conflitos pela orientação, isto é, os fins, 
os meios e os limites desses processos. Para os controladores do poder, o controle do capital e do mercado era e é o que decide os fins, os meios e os limites do processo. O mercado é o mínimo, mas também o limite da possível igualdade social entre as pessoas.

A inserção de novos projetos políticos não parece ser possível em um espaço restrito à discussão de economia e gerenciamento. Na verdade, este espaço é avesso às possibilidades formuladas fora de suas regras e de sua contabilidade. Nos termos de Mbembe (2020), trata-se da política que nega o pluralismo e a diversidade, posto que não se permite relacionar com zonas de indeterminação. Por isso, a mobilização e a atuação nos espaços institucionalizados sobre a gestão de águas seguem limitadas a uma lógica específica que demanda a posse de saberes já legitimados no debate. Há, portanto, uma domesticação dos saberes e é sob essa perspectiva que a condição de subalternidade no debate públicoambiental sobre a água se cristaliza.

Dessa maneira, à medida em que discutir o poder na contemporaneidade implica necessariamente abordar os saberes, as formas de subjetivação da relação sociedade-meio ambiente, implicadas nos instrumentos econômicos de gestão das águas, produzem simultaneamente as verdades sobre o bom uso e sobre a boa gestão (racional) do recurso. A produção dessa verdade, como outras formas de verdade, atravessa a experiência dos diferentes grupos e classes sociais na relação com o meio ambiente e com sua própria história. De tal sorte que falar de gestão ambiental traz consigo a gestão dos corpos sociais e das formas de subjetivação da dominação e da subalternidade.

\section{À guisa de conclusão}

O objetivo deste artigo foi compreender a experiência de criação do Conselho Mundial da Água e interpretar sua 
atuação no contexto do debate público-ambiental internacional. Para tanto, foram perseguidas pistas analíticas que revelavam como formas de discursos de saber-poder afirmaram certos mecanismos de classificação e hierarquização da experiência social sobre a gestão da água.

O trânsito dos agentes fundadores do Conselho, e de seus presidentes, é um importante indicador dos recursos simbólicos mobilizados no fazer da instituição. A circulação internacional desses agentes fez-se em espaços consolidados de produção de saber-poder, amparadas em epistemologias coloniais da divisão norte e sul. Esse fato revela-se marcante, inclusive, no modo como os países do sul serão inscritos no debate internacional, como espaços a serem conquistados pela racionalidade gestora das tecnologias de saber do norte.

$\mathrm{Na}$ argumentação dos documentos do Conselho e dos Fóruns Mundiais da Água, também foi possível identificar a recorrência para um modelo específico de gestão amparado em três elementos. O primeiro é o armamento técnico e neutro, sustentado pelo conhecimento científico. Esse elemento não só possibilita que o discurso passe por não subjetivo, como também o qualifica para descrever o cenário contemporâneo da água. Em outras palavras, através desse recurso é possível afirmar objetivamente quais países em desenvolvimento não possuem tecnologia para resolver seus problemas em relação à água, tampouco possuem recursos financeiros para aplicar em investimentos, pois o diagnóstico técnico também apresenta a demanda de um montante astronômico de capital para, por exemplo, contemplar o direito à água a todos.

Isso remete ao segundo elemento que sustenta a argumentação: a gramática utilitarista da economia neoclássica, base teórico-abstrata do ideário neoliberal. O mercado é, segundo essa concepção, a única esfera capaz de oferecer 
o capital e a tecnologia necessária para a solução da crise hídrica, logo, é a falta do mercado que leva à crise da água.

Por fim, o terceiro elemento é bastante singular e consiste na participação e na diversidade, fundamentais para a legitimação desse modelo específico. Entretanto, ambas se dão de forma domesticada e em espaços onde o universo do debate está aprisionado em fronteiras firmes que determinam, a partir da prerrogativa prática, técnica e econômica, o que é ou não possível em relação ao tema.

A existência do Conselho e o discurso de saber que a entidade logrou disseminar nos Fóruns Mundiais da Água vieram dilatar as esferas de influência de certos grupos empresariais e financeiros no debate internacional sobre água, ou seja, para enfrentar as situações de escassez, ausência de saneamento e a reprodução da pobreza correlata. Dessa maneira, o Conselho insistiria no discurso unívoco da abertura de novas frentes de investimento para o capital privado, com segurança jurídica e segurança política para a fixação de novos mercados para o negócio da água. Por conseguinte, para fazer circular os imperativos morais deste discurso, os Fóruns tiveram papel estratégico, contribuindo para a justificação de uma vontade histórica de saber-poder sobre o recurso e o meio ambiente em geral.

\section{Rodrigo de Freitas Espinoza}

Doutor em Sociologia pela Universidade Federal de São Carlos. Estágio de doutorado sanduíche no Departamento de Estudos Étnicos da Universidade da Califórnia (Berkeley). Realiza pesquisa na área de Sociologia Ambiental.

\section{Rodrigo Constante Martins}

Professor do Departamento de Sociologia, do Programa de Pós-graduação em Sociologia e do Programa de Pósgraduação em Ciências Ambientais da Universidade Federal 
de São Carlos (UFSCar). Pós-doutorado pela École des Hautes Études en Sciences Sociales de Paris.

\section{Bibliografia}

ACSELRAD, Henri; MELLO, Cecilia Campelo do Amaral; BEZERRA, Gustavo das Neves. 2009. O que é justiça ambiental. Rio de Janeiro: Garamond.

BOLTANSKI, Luc; CHIAPELLO, Ève. 2009. O novo espírito do capitalismo. São Paulo: Editora WMF Martins Fontes.

BOLTANSKI, Luc; THÉVENOT, Laurent. 1991. De la justification: les économies de la grandeur. Paris: Gallimard.

CASTRO, José Esteban. 2007. Water governance in the twentieth-first century. Ambiente e Sociedade, v. 10, n. 2, pp. 97-118.

CASTRO-GÓMEZ, Santiago. 2011. Crítica de la razón latinoamericana. $2^{-a}$ Ed. Bogotá: Editorial Pontifícia Universidad Javeriana.

CORONIL, Fernando. 2005. Natureza do pós-colonialismo: do eurocentrismo ao globocentrismo. In: LANDER, Edgardo (org.). A colonialidade do saber: eurocentrismo e ciências sociais. Perspectivas latinoamericanas. Buenos Aires: CLACSO, pp. 105-132. (Colección Sur Sur).

ESPINOZA, Rodrigo de Freitas. 2016. Rivalidade entre os polos: a construção discursiva do Conselho Mundial da Água. Tese de doutorado em Sociologia. São Carlos: UFSCar. Disponível em: https://bit.ly/3hPeuSv. Acesso em: 19 jul. 2021.

FERDINAND, Malcom. 2019. Une écologie décoloniale. Penser l'écologie depuis le monde caribéen. Paris: Éditions du Seuil.

FOUCAULT, Michel. 1996. A ordem do discurso. São Paulo, Loyola. FOUCAULT, Michel. 2018. História da sexualidade - I: A vontade de saber. $7^{\mathrm{a}}$ ed. Rio de Janeiro: Paz \& Terra.

GROSFOGUEL, Ramón. 2012. Descolonizar as esquerdas ocidentalizadas: para além das esquerdas eurocêntricas rumo a uma esquerda transmoderna descolonial. Contemporânea, v. 2, n. 2. pp.337-362.

MARTINS, Rodrigo Constante. 2013. A construção social da economia política da água. Sociologia, problemas e práticas, n. 73, pp.111-130.

MARTINS, Rodrigo Constante. 2015. A classificação disciplinar no mercado dos enunciados ambientais. Revista Brasileira de Ciências Sociais, v. 30, n. 87, pp.97-113.

MBEMBE, Achille. 2020. Brutalisme. Paris. La Découverte.

MIGNOLO, Walter. 2010. Desobediencia epistémica: retórica de la modernidad, lógica de la colonialidad y gramática de la descolonialidad. Buenos Aires: Ediciones Del Signo. 
MORENO, Alejandro. 2005. Superar a exclusão, conquistar a equidade: reformas, políticas e capacidades no âmbito social. In: LANDER, Edgardo (org.). A colonialidade do saber: eurocentrismo e ciências sociais. Perspectivas latino-americanas. Buenos Aires: CLACSO, pp. 187-202.

PEARCE, David. 1985 Economia ambiental. México: Fundo de Cultura Econômica.

PEARCE, David; TURNER, Kerry. 1991. Economics of natural resources and the environment. Baltimore: The Johns Hopkins University Press.

QUIJANO, Aníbal. 2005. Colonialidade do poder, eurocentrismo e América Latina. In: LANDER, Edgardo (org.). A colonialidade do saber: eurocentrismo e ciências sociais. Perspectivas latino-americanas. Buenos Aires: CLACSO, pp. 227-278.

RIBEIRO, Wagner Costa. 2008. Geografia política da água. São Paulo: Annablume.

RIBEIRO, Wagner Costa. 2010. A ordem ambiental internacional. 2. ed. São Paulo: Contexto.

SMITH, Adam. 2015. Teoria dos sentimentos morais. $2^{\underline{a}}$ ed. São Paulo: Editora WMF Martins Fontes.

WORLD WATER COUNCIL. 2000. World water vision: making water everybody business. London: Earthscan. Disponível em: https://bit.ly/3it91Qm. Acesso em: 22 nov. 2017.

WORLD WATER COUNCIL. 2003a. Triennial Report: 2000-2003. Marseille. Disponível em: https:/ / bit.ly/2UYLajD. Acesso em: 19 jan. 2018. WORLD WATER COUNCIL. 2003b. Analisys of the $3^{\text {rd }}$ World Water Forum: march 16-23 - Kyoto, Shiga E゚ Osaka, Japan. Marseille. Disponível em: https://bit.ly/3wNvMnf. Acesso em: 19 mar. 2018.

WORLD WATER COUNCIL. 2003c. The $3^{\text {id }}$ World Water Forum Final Report: march 16-23 - Kyoto, Shiga Eं Osaka, Japan. Japan, Marseille. Disponível em: https:/ /bit.ly/3Bj9hKr. Acesso em: 19 mar. 2017.

WORLD WATER COUNCIL. 2012a. Hydro-diplomacy in motion: World Water Council 2010-2012. Marseille. Disponível em: https:/ /bit.ly/3BINTUM. Acesso em: 19 fev. 2017.

WORLD WATER COUNCIL. 2012b. $6^{\text {th }}$ World Water Forum Ministerial Declaration. Marseille. Disponível em: https://bit.ly/2UYNOpz. Acesso em: 19 ago. 2018.

WORLD WATER COUNCIL. 2015. Delivering a pact for water security: World Water Council Triennial report 2013-2015. Marseille. Disponível em: https://bit.ly/3itd534. Acesso em: 19 fev. 2019. 
WORLD WATER COUNCIL. 2017. Water for Africa. Initiative Consultancy Assignment. Marseille. Disponível em: https://bit.ly/3iuo3oS. Acesso em: dez. 2020.

WORLD WATER COUNCIL. 2018a. Ten Actions for Financing Water Infrastructure. Marseille. Disponível em: https://bit.ly/3xRprIV. Acesso em: dez. 2020.

WORLD WATER COUNCIL. 2018b. Global Water Security: Lessons Learnt and Long-Term Implications. Marseille: World Water Council and Ministry of Water Resources-China. 


\section{TECNOLOGIAS DE SABER-PODER SOBRE AS ÁGUAS: A EXPERIÊNCIA DO CONSELHO MUNDIAL DA ÁGUA}

RODRIGO DE FREITAS ESPINOZA

\section{RODRIGO CONSTANTE MARTINS}

Resumo: Este trabalho visa caracterizar a produção discursiva do Conselho Mundial da Água, criado em 1996 com o objetivo de debater e mobilizar ações internacionais sobre a água. Para tal tarefa, o artigo desenvolve a análise de documentos e relatórios publicados pelo Conselho e da organização dos Fóruns Mundiais da Água realizados no período, articulando o referencial dos estudos pós-coloniais com a analítica do poder de Michel Foucault, além de utilizar a noção de justificação moral da sociologia pragmática, para compreender os imperativos de discurso no debate internacional sobre meio ambiente.

Palavras-chave: Governança da Água; Sociedade e Recursos Hídricos; Colonialidade e Meio Ambiente; Conselho Mundial da Água.

\section{WATER POWER-KNOWLEDGE TECHNOLOGIES: THE EXPERIENCE OF THE WORLD WATER COUNCIL}

Abstract: This essay describes the discursive production of the World Water Council, created in 1996 to foster international debate and actions regarding water. To this end, we analyze documents and reports published by the Council and the World Water Forums organization held in the period. To understand the discourse imperatives on the international debate about the environment, the study articulates the framework of post-colonial studies with Michel Foucault's analysis of power, while also borrowing the notion of moral justification developed by pragmatic sociology.

Keywords: Water Governance, Society and Water Resources, Coloniality and Environment, World Water Council.

Recebido: 21/04/2021 Aprovado: 12/07/2021 